\title{
Can ridge-furrow plastic mulching replace irrigation in dryland wheat and maize cropping systems?
}

\section{Stefani Daryanto, Lixin Wang*, Pierre-André Jacinthe}

Department of Earth Sciences, Indiana University-Purdue University Indianapolis, Indianapolis, IN 46202, USA

*Corresponding author

Lixin Wang

Department of Earth Sciences

Indiana University Purdue University Indianapolis

Indianapolis, IN 46202, USA

Phone: +1 3172747764

Email: lxwang@iupui.edu

This is the author's manuscript of the article published in final edited form as:

Daryanto, S., Wang, L., \& Jacinthe, P.-A. (2017). Can ridge-furrow plastic mulching replace irrigation in dryland wheat and maize cropping systems? Agricultural Water Management, 190(Supplement C), 1-5. https://doi.org/10.1016/j.agwat.2017.05.005 


\begin{abstract}
Dryland crop production requires significant water investments, but problems associated with irrigation have been observed in many dryland regions (e.g., China, Australia and the Mediterranean basin). A key strategy for maintaining crop yields without over-exploiting the scarce water resource is by increasing water use efficiency (WUE). Plastic mulching technology for wheat and maize has been commonly used in China, but their effect on yield, soil water content, evapotranspiration (ET), and WUE has not been compared with traditional irrigation. Using a meta-analysis approach, we quantitatively examined the efficacy of plastic mulching in comparison with traditional irrigation in the same region. By covering the ridges with plastic and channeling rainwater into a very narrow planting zone (furrow), our results showed that plastic mulching resulted in a yield increase comparable to irrigated crops but used $24 \%$ less water in comparison with irrigation due primarily to a much greater WUE and better retention of soil water. The higher WUE in plastic-mulched croplands was likely a result of a greater proportion of available water being used for transpiration (T) than evaporation (E). Currently production costs and residual plastic pollution hinder worldwide adoption of the technique, despite being a promising strategy for dryland cropping systems.
\end{abstract} Keywords: agricultural production, China, evaporation, meta analysis, transpiration, water use efficiency 


\section{Introduction}

Dryland crop production remains the primary source of staple food production for the majority of densely-populated regions such as China, sub-Saharan Africa, India, and the Mediterranean. With aridity index (i.e., ratio between precipitation and potential evapotranspiration $\left(\mathrm{ET}_{0}\right)$ ) $\leq 0.65$ (Wang et al., 2012), crop production in drylands is a continuous exercise to allocate the limited rainwater supply to meet the ET demand of growing crops. Therefore, increasing water use efficiency (WUE; crop yield per unit of available water) in dryland cropping systems is essential in order to maximize productivity (Bennie and Hensley, 2001; Lu et al., 2016a).

The challenges facing dryland crop production are further amplified with a changing climate (i.e., more frequent drought) as most climate models suggest that climate change will be more detrimental towards dryland (i.e., rainfed) than to fully irrigated crop production systems (Piao et al., 2010). In countries like China where dryland regions account for $65 \%$ of the total arable land and contribute the majority of the nation's food production (Deng et al., 2006), supplementary irrigation is necessary to ensure food security. Low WUE associated with irrigation in the dry regions, however, has caused severe environmental problems, including groundwater decline and drying rivers (Deng et al., 2006), seawater intrusion and soil salinization (Cudennec et al., 2007; Lambers, 2003; Narayan et al., 2007) as reported in China, Australia and the Mediterranean.

The use of water-saving strategies is therefore critical for dryland cropping systems considering that rainfall is not only low in absolute amount but is also unevenly distributed. During the last five decades (1950-2000), grain production has increased dramatically from about $113 \times 10^{6}$ tons to $512 \times 10^{6}$ tons in China ( 3\% increase annually) (Cui et al., 2010). Currently, China is the largest producer of wheat and only second after the United States (US) in terms of global maize production (Daryanto et al., 2016). One water-saving strategy that may have contributed to the increase is the adoption of plastic mulching technology that is most commonly used in northern China for maize and wheat production. Nationwide, plastic mulching has increased maize and wheat 
grain production by 33.7\% and 33.2\%, respectively (Liu et al., 2014). Food security and the growth of grain production have been an ongoing priority for the Chinese government, who have provided farmers with a guaranteed amount of plastic mulch at low, subsidized prices since the agricultural reform initiated in 1979 (Colby et al., 1991; Ni, 2013). The technique, introduced in 1978, has gained popularity ever since (Zhou et al., 2009) and, over the past two decades, the use of plastic mulch has increased in all provinces and regions of China. Between 1990 and 2000 alone, 80\% of the world's plastic-mulched surface was found in China with 25\% annual growth rate (Espi et al., 2006). While the lowest estimated increase rate of cultivation area covered by plastic mulch would be about 5\% over the next ten years if the covered crop area increased from the current $20 \times 10^{6}$ ha to $30 \times 10^{6}$ ha, the number could be higher (8-10\%) if the increasing covered crop area went above $30 \times 10^{6}$ ha (Liu et al., 2014).

Plastic mulch conserves water in areas where irrigation is limited or not available, and protects emerging crops from low spring soil temperature (Zhou et al., 2009). The use of organic mulch (e.g., straw mulch), on the other hand, has been limited due to its rapid decomposition and its adverse effects on soil temperature (i.e., too cold during winter or spring) (Chen et al., 2015). In general, the plastic mulching technology is deployed in a ridge-furrow system; the plastic mulch is placed on top of the ridge to concentrate the flow of water from the ridge to the furrow where the crops are planted. From now on, the term 'plastic mulching' will be used to refer to the aforementioned description. The use of plastic mulching, however, requires larger input of money and labor on an annual basis, and may result in reduced subsoil water with increasing plant growth and transpiration rate compared to traditional irrigation (Li et al., 1999; Liu et al., 2009). The effectiveness of plastic mulching also varies, depending on the type of surface cover on the furrow, climate and soil conditions, as well as their interactions (Han et al., 2014), highlighting the importance of quantitatively examining the efficacy of this water-saving strategy. 
In this communication, we compare plastic mulching and traditional irrigation in terms of improving wheat and maize yield, as well as relevant crop and soil parameters (e.g., ET, WUE, and soil water content). We used a meta-analysis approach to summarize the results from independent experiments (Hedges et al., 1999) across different climatic zones and soil types. Using China’s dryland crop production as an example, our results can help to quantitatively evaluate plastic mulching and develop water-saving strategies in other semi-arid regions that are severely affected by drought and water shortages.

\section{Methods}

Peer-reviewed journal articles published in English from 1985 to 2016 were collected to build the database based on Web of Science search using the following sets of keywords: (i) wheat or maize, (ii) film mulch or plastic mulch or plastic cover, and (iii) water stress or water deficit or drought or irrigation deficit. We replaced the phrases ‘film mulch', 'plastic mulch' and 'plastic cover' with 'irrigation' and 'China' to search for articles discussing supplementary irrigation specific to the region. The search for mulching and irrigation articles resulted in 78 and 394 articles, respectively, but only articles from China that met the following criteria were included in the database: (i) the experiments were conducted under field conditions where the effect of irrigation or plastic mulching was compared with flat (even or level topography), rainfed conditions, (ii) the reported plants were monoculture cereals of maize (Zea mays) and wheat (i.e., bread wheat; Triticum aestivum), and (iii) the articles reported crop response as grain yield. This resulted in 49 articles (see list in the Supplementary Information) that all came from regions with similar agro-ecological features. If the articles reported a combination with other treatments (e.g., addition of fertilizer, cultivar, or spacing width), the effects of these treatments were averaged across the mulching or irrigated condition. By averaging the response, we avoided over-representation of a study, reduced publication bias, increased the reliability of our results, and ensured the independence of each data entry (Lu et al., 2016b). We did not differentiate among irrigation methods and only recorded the amount of water 
applied, since there have been many studies showing that the type of irrigation was not significant in comparison to the amount of water in determining yield, including in the drylands (Erdem et al., 2006; Onder et al., 2005; Sammis, 1980; Shalhevet et al., 1983; Ünlü et al., 2006). We also recorded the amount of rainfall received during the growing season to understand the extent of irrigation relative to the rainfall. The ratio between irrigation and rainfall ranged between 0.3 and 4.9 . If a study was conducted across different years or study sites with similar agro-ecological features, or reported more than one amount of irrigation, all observations were considered independent and included in the database (Daryanto et al., 2016).

The magnitude of yield, total ET, WUE, and average soil water content $(0-20 \mathrm{~cm})$ responses throughout the crop growing season were examined based on four treatments: (i) irrigation and three different types of mulch that covered the furrow: (ii) plastic, (iii) straw, and (iv) no cover or bare (Fig. 1). No additional irrigation was provided for each of the mulching treatments. The number of observations (samples) for each treatment are available in the corresponding figure of the Results section. To compare the differences in crop or soil response ratio between each treatment, metaanalysis was used to construct the confidence intervals. In order to include those studies that did not adequately report sample size or standard deviation, we performed an unweighted analysis using the $\log$ response ratio $(\operatorname{lnR})$ to calculate bootstrapped confidence limits using the statistical software MetaWin 2.0 (Rosenberg et al., 2000). The response ratio is the ratio between the outcome of treatment group (i.e., irrigation or mulched) to that of the control group (i.e., flat, rainfed condition) to estimate the proportional change resulting from irrigation or mulching. We performed a simple diagnostic test using the formula following Lajeunesse (2015) to improve the reliability of $\ln R$ in estimating the effect size. The results of the calculation are provided in Supplementary Table S1. Bootstrapping was also iterated 9999 times to improve the probability that the confidence interval was calculated around the cumulative mean effect size for each categorical variable. The difference between the control and irrigated or mulched condition was considered significant if the bootstrap 
confidence intervals did not overlap with zero, while the difference among treatments was significant if the intervals did not overlap with each other $(P<0.05)$ (Curtis and Wang, 1998).

\section{Results}

Our results show that both irrigation and plastic mulching increased soil water content, WUE, and crop yield when compared to flat, rainfed cropping systems (Figs. 2a-d). There were, however, different extents of soil water content, WUE and yield increase with different furrow cover when compared with traditional irrigation. The absence of cover on the furrow resulted in the lowest soil water content increase (6\%) when compared with straw-covered (13\%) or plastic-covered furrow (19\%) and irrigated condition (22\%; Fig. 2a). Plastic mulching with plastic-covered furrow successfully increased crop yield to a level comparable to that of irrigated crops (Fig. 2b), although the crops received $24 \%$ more water on average (i.e., mean irrigation:rainfall $=1.24 \pm 0.94$ ) for the irrigated treatment. Covering the furrow with straw, however, did not increase yield compared with uncovered furrow (Fig. 2b). Despite producing higher yield (i.e., 50\% increase) compared with flat, rainfed cropping system, irrigated crops had the lowest WUE (3\%) compared with plastic-mulched crops (18-37\%; Fig. 2c). Regardless of the type of furrow cover, there was a much higher water loss through ET with irrigation (43\%) in comparison to plastic mulching (<10\%) (Fig. 2d).

\section{Discussion}

Although soil water content increase between straw- and plastic-covered furrow was similar (Fig. 2a), plastic-covered furrow tended to produce higher crop yield compared to straw-covered furrow

(Fig. 2b). Increasing root weight density, root length density and root diameter of the plastic-covered furrow (Gao et al., 2014) allowed the crops to utilize deep soil moisture (Zhou et al., 2009), minimizing loss through deep drainage and leading to higher crop yield.

Differences in soil temperature during germination and seedling establishment might also contribute to the disparity in yield since plastic cover increased soil temperature as opposed to straw 
mulch. Low soil temperature during early growth (i.e., early spring) associated with straw mulch might have delayed metabolic processes in wheat plants and later retarded the differentiation of reproductive organs (Li et al., 1999). The addition of a plastic layer in the furrow, on the other hand, resulted in faster warming of soil but slower cooling at night (Ham et al., 1993). This is particularly important at corn seedling stage since low soil temperature in the unmulched control was too low to allow the crop to reach maturity (Zhou et al., 2009). Similarly, early development of wheat plants with higher soil temperature allowed shoots to emerge earlier and consequently had a longer phenostage, increased tiller number, and enhanced early spike differentiation, including the production of optimum spikelet number and grain number per spike (Li et al., 1999). With a longer reproductive period (i.e., flowering to harvesting), there is greater transport of assimilates from vegetative to reproductive organs, resulting in higher grain yield (Li et al., 1999). This effect of soil temperature, however, was less obvious in irrigated crops because farmers in northern China traditionally followed a late sowing procedure (Zhang et al., 1998). The effect of soil temperature on crop performance would decrease rapidly with increasing leaf area index since soil temperature only controlled the rate of crop development when the plant meristem was within the soil (Chen et al., 2007).

The absence of any cover in the furrow generated the lowest increase in soil water content (Fig. 2a), probably due to runoff and excessive evaporative water loss in the unmulched furrow. Similar results were obtained with straw mulch, probably because of rapid decomposition of the straw (Chen et al., 2015). With higher magnitude of water loss to evaporation (E) during the end of growing season (i.e., during summer when air temperature was also high) (Li et al., 2013), it was unsurprising that there was lower yield associated with unmulched furrows (Fig. 2b). Maize, in particular, was sensitive to drought during the reproductive phase, to the point that yield could not be recovered even with subsequent irrigation due to flower sterility and asynchrony between anthesis and silking (Daryanto et al., 2016). 
Our results show that plastic mulching could be considered an effective water-saving strategy since it simultaneously increased WUE and yield, particularly when combined with a plastic-covered furrow (Fig. 1, Fig. 2c). Despite generating crop yields similar to irrigated systems, plastic mulching in combination with plastic-covered furrow had much higher WUE (Fig. 2c). The addition of plastic cover on the furrow reduced the gaps by which water could evaporate, consistent with the data from $\mathrm{Li}$ et al. (2003) where increasing surface perforation of the plastic mulch from $0 \%$ to $30.5 \%$ decreased the restraining effect on E by $69.26 \%$ to $11.82 \%$, respectively. By reducing the majority of water loss from E, increased soil water content in the plastic-covered furrow thus allowed more of the available water to be used by transpiration (T). In contrast, a much higher $\mathrm{E}$ rather than from plant T in irrigated fields could lead to low WUE (Fig. 2c). Indeed, a study estimated that the E:ET ratio of plastic mulch could be as low as 0.06 as opposed to 0.32 in unmulched fields (Li et al., 2013), allowing the mulched field to support better plant growth. Improved plant growth generated a positive feedback through the shading effect of an extended plant canopy, which reduced wind speed, the amount of solar radiation reaching the soil and soil temperature, ultimately reduced evaporative water loss (Cooper et al., 1987). Conversely, despite the crop yield increase, supplementary irrigation could not be considered an ideal management strategy in this water-scarce region because of the much higher ET and lower WUE compared to the plastic mulching treatment (Fig. 2d).

While plastic mulching could be a promising strategy to improve crop yield in dryland regions, recent investigation suggested that the amount of plastic residue could range from 50 to 260 $\mathrm{kg} \mathrm{ha}^{-1}$ in cultivated lands (Liu et al., 2014). This plastic pollution can lead to unsustainable farming systems due to soil structure deterioration (e.g., block water infiltration and nutrient movement), possible salinization, and the release of harmful chemicals into soil and water systems (e.g., phthalate esters, aldehydes and ketones) (Liu et al., 2014). These potential problems need a thorough examination and require the formulation of countermeasures that meet policy, regulatory and technological requirements. Using thicker plastic films $(0.015-0.02 \mathrm{~mm}$ vs current $0.008 \mathrm{~mm})$ which 
have a longer service life or biodegradable plastic material (Liu et al., 2014) could emerge as a viable short-term option to improve crop WUE, although the technology could increase production costs. These costs consist of the initial investment to purchase the plastic film (USD $102 \mathrm{ha}^{-1}$ ) and the cost of mulching and disposing of the film (USD $62 \mathrm{ha}^{-1}$ ), resulting in a total of 164 USD ha-1 (vs 112 USD ha-1 for irrigation which yielded the maximum cost benefit ratio) (Xie et al., 2005). This cost might deter the adoption of plastic mulching technology by poor smallholders. In the future, the development of low-cost biodegradable plastic mulch film must be a priority to eliminate plastic pollution and to control production costs. If these limitations are addressed successfully, the use of plastic mulching in China may serve as the standard for improving WUE and crop yield in other dryland cropping systems.

\section{Conclusions}

Plastic mulching technology is a promising strategy to improve WUE and crop yield to a level comparable to irrigated croplands in the drylands due to its ability to increase soil water content and to direct most of the available water to $\mathrm{T}$ instead of $\mathrm{E}$. The effectiveness of plastic mulching technology, however, was most enhanced by the presence of a plastic cover on the furrow to reduce soil evaporation, which otherwise would have occurred at a rate similar to uncovered furrows. Covering the furrow with straw did not result in improved crop yield, as yield was similar to uncovered furrow. Despite its effectiveness, high production costs (i.e., purchasing, laying, and disposing of the plastic) and plastic pollution limit the adoption of current plastic mulch technology, particularly in poor rainfed agricultural regions.

\section{Acknowledgements}

This research was supported by USDA grant (2014-51130-22492).

\section{References}


Bennie, A., Hensley, M., 2001. Maximizing precipitation utilization in dryland agriculture in South Africa—a review. Journal of Hydrology 241, 124-139.

Chen, S., Zhang, X., Pei, D., Sun, H., Chen, S., 2007. Effects of straw mulching on soil temperature, evaporation and yield of winter wheat: field experiments on the North China Plain. Annals of Applied Biology 150, 261-268.

Chen, Y., Liu, T., Tian, X., Wang, X., Li, M., Wang, S., Wang, Z., 2015. Effects of plastic film combined with straw mulch on grain yield and water use efficiency of winter wheat in Loess Plateau. Field Crops Research 172, 53-58.

Colby, W., Crook, F., Tuan, F., Webb, S., Wildman, M., 1991. China's Agricultural Commodity Policies in the 1980's, United States Department of Agriculture Economic Research Service, China Agriculture and Trade Report (RS-91-3) July 1991, pp. 38-45.

Cooper, P., Gregory, P., Keatinge, J., Brown, S., 1987. Effects of fertilizer, variety and location on barley production under rainfed conditions in Northern Syria 2. soil water dynamics and crop water use. Field Crops Research 16, 67-84.

Cudennec, C., Leduc, C., Koutsoyiannis, D., 2007. Dryland hydrology in Mediterranean regions—a review. Hydrological Sciences Journal 52, 1077-1087.

Cui, Z., Chen, X., Zhang, F., 2010. Current nitrogen management status and measures to improve the intensive wheat-maize system in China. Ambio 39, 376-384.

Curtis, P.S., Wang, X., 1998. A meta-analysis of elevated $\mathrm{CO}_{2}$ effects on woody plant mass, form, and physiology. Oecologia 113, 299-313.

Daryanto, S., Wang, L., Jacinthe, P.A., 2016. Global synthesis of drought effects on maize and wheat production. PLOS ONE 11, e0156362. 
Deng, X.-P., Shan, L., Zhang, H., Turner, N.C., 2006. Improving agricultural water use efficiency in arid and semiarid areas of China. Agricultural Water Management 80, 23-40. Erdem, T., Erdem, Y., Orta, H., Okursoy, H., 2006. Water-yield relationships of potato under different irrigation methods and regimens. Scientia Agricola 63, 226-231.

Espi, E., Salmeron, A., Fontecha, A., García, Y., Real, A., 2006. Plastic films for agricultural applications. Journal of Plastic Film and Sheeting 22, 85-102.

Gao, Y., Xie, Y., Jiang, H., Wu, B., Niu, J., 2014. Soil water status and root distribution across the rooting zone in maize with plastic film mulching. Field Crops Research 156, 40-47. Ham, J.M., Kluitenberg, G., Lamont, W., 1993. Optical properties of plastic mulches affect the field temperature regime. Journal of the American Society for Horticultural Science 118, 188193.

Han, J., Jia, Z., Wu, W., Li, C., Han, Q., Zhang, J., 2014. Modeling impacts of film mulching on rainfed crop yield in Northern China with DNDC. Field Crops Research 155, 202-212. Hedges, L.V., Gurevitch, J., Curtis, P.S., 1999. The meta-analysis of response ratios in experimental ecology. Ecology 80, 1150-1156.

Lajeunesse, M., 2015. Bias and correction for the log response ratio in ecological metaanalysis. Ecology 96, 2056-2063.

Lambers, H., 2003. Introduction, dryland salinity: a key environmental issue in southern Australia. Plant and Soil 257, 5-7.

Li, F.-M., Guo, A.-H., Wei, H., 1999. Effects of clear plastic film mulch on yield of spring wheat. Field Crops Research 63, 79-86. 
Li, S., Wang, Z., Li, S., Gao, Y., Tian, X., 2013. Effect of plastic sheet mulch, wheat straw mulch, and maize growth on water loss by evaporation in dryland areas of China. Agricultural Water Management 116, 39-49.

Li, Y., Shao, M., Wang, W., Wang, Q., Horton, R., 2003. Open-hole effects of perforated plastic mulches on soil water evaporation. Soil Science 168, 751-758.

Liu, C., Jin, S., Zhou, L., Jia, Y., Li, F., Xiong, Y., Li, X., 2009. Effects of plastic film mulch and tillage on maize productivity and soil parameters. European Journal of Agronomy 31, 241-249. Liu, E., He, W., Yan, C., 2014. ‘White revolution’to ‘white pollution’—agricultural plastic film mulch in China. Environmental Research Letters 9, 091001.

Lu, X., LL, L., L, W., GD, J., MF, M., DA., G., 2016a. Partitioning of evapotranspiration using a stable isotope technique in an arid and high temperature agricultural production system. Agricultural Water Management doi:10.1016/j.agwat.2016.08.012.

Lu, X., Wang, L., McCabe, M.F., 2016b. Elevated $\mathrm{CO}_{2}$ as a driver of global dryland greening. Scientific reports 6, 20716.

Narayan, K.A., Schleeberger, C., Bristow, K.L., 2007. Modelling seawater intrusion in the Burdekin Delta irrigation area, North Queensland, Australia. Agricultural Water Management 89, 217-228.

Ni, H., 2013. Agricultural domestic support and sustainable development in China, ICTSD Programme on Agricultural Trade and Sustainable Development, Geneva, Switzerland.

Onder, S., Caliskan, M.E., Onder, D., Caliskan, S., 2005. Different irrigation methods and water stress effects on potato yield and yield components. Agricultural Water Management 73, 73-86. 
Piao, S., Ciais, P., Huang, Y., Shen, Z., Peng, S., Li, J., Zhou, L., Liu, H., Ma, Y., Ding, Y., 2010. The impacts of climate change on water resources and agriculture in China. Nature 467, 43-51.

Rosenberg, M.S., Adams, D.C., Gurevitch, J., 2000. MetaWin: Statistical Software for MetaAnalysis Version 2.0. Sinauer Associates, Inc., Sunderland, Massachusetts.

Sammis, T.W., 1980. Comparison of sprinkler, trickle, subsurface, and furrow irrigation methods for row crops. Agronomy Journal 72, 701-704.

Shalhevet, J., Shimshi, D., Meir, T., 1983. Potato irrigation requirements in a hot climate using sprinkler and drip methods. Agronomy Journal 75, 13-16.

Ünlü, M., Kanber, R., Şenyigit, U., Onaran, H., Diker, K., 2006. Trickle and sprinkler irrigation of potato (Solanum tuberosum L.) in the Middle Anatolian Region in Turkey. Agricultural Water Management 79, 43-71.

Wang, L., D'Odorico, P., Evans, J., Eldridge, D., McCabe, M., Caylor, K., King, E., 2012.

Dryland ecohydrology and climate change: critical issues and technical advances. Hydrology and Earth System Sciences 16, 2585-2603.

Xie, Z.-k., Wang, Y.-j., Li, F.-m., 2005. Effect of plastic mulching on soil water use and spring wheat yield in arid region of northwest China. Agricultural Water Management 75, 71-83. Zhang, J., Sui, X., Li, B., Su, B., Li, J., Zhou, D., 1998. An improved water-use efficiency for winter wheat grown under reduced irrigation. Field Crops Research 59, 91-98.

Zhou, L.-M., Li, F.-M., Jin, S.-L., Song, Y., 2009. How two ridges and the furrow mulched with plastic film affect soil water, soil temperature and yield of maize on the semiarid Loess Plateau of China. Field Crops Research 113, 41-47. 


\section{Figure Captions}

Fig. 1. Schematic diagram of the water harvesting strategy of ridge-furrow plastic mulching (i.e., plastic-covered ridge with different furrow cover).

Fig. 2. Changes in soil water content (a), yield (b), WUE (c) and ET (d), expressed as a ratio between the treatment and the control. The treatment is either rainfed, plastic mulched ridge with different furrow covers or flat, irrigated cropping system while the control is a flat, rainfed cropping system. A positive value indicates an increase in the ratio due to the treatment. Letter ' $n$ ' indicates the number of samples, $P$ values indicate statistical significance between different treatments. Note differences in the scale of the $\mathrm{x}$-axis. 


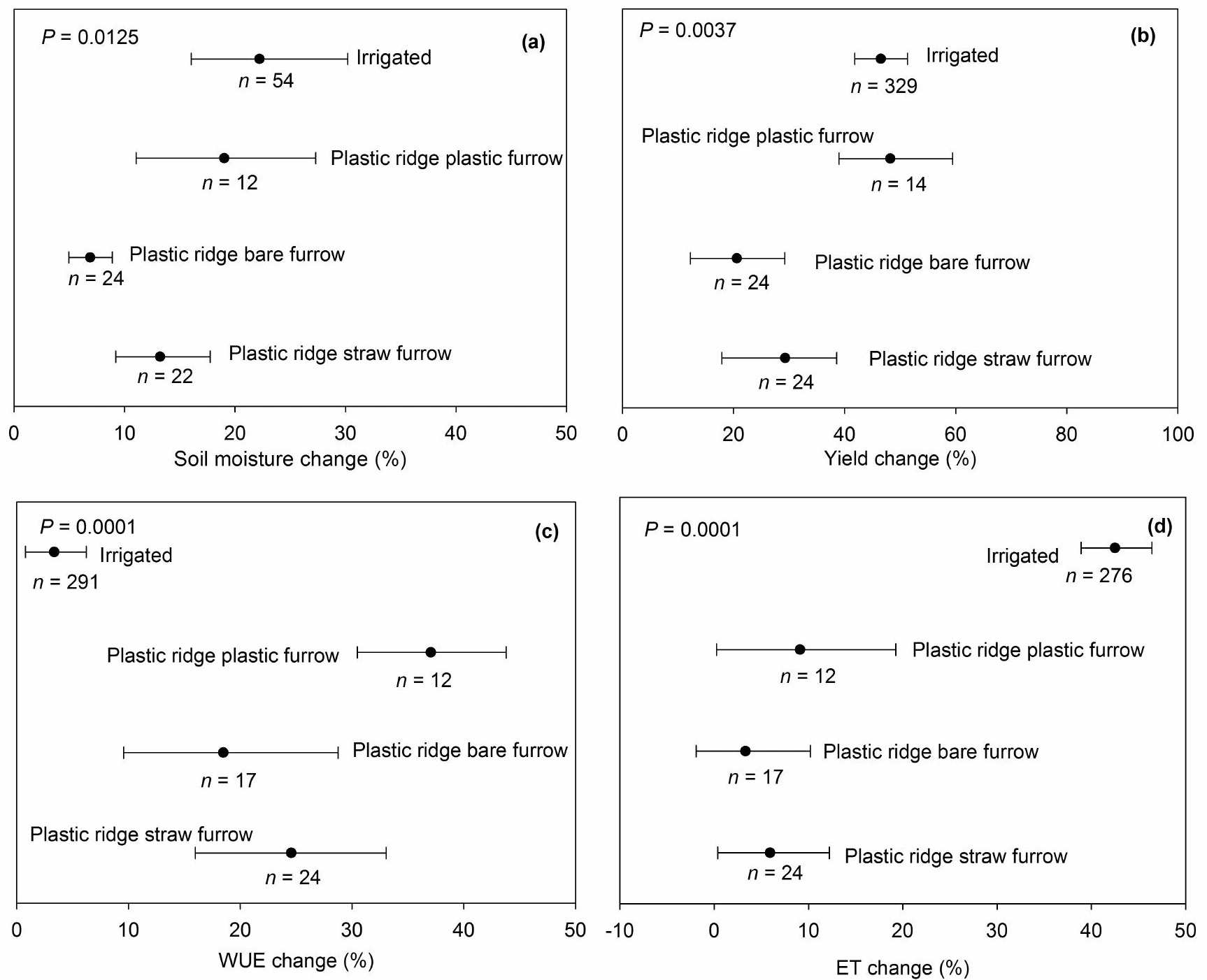